\title{
Aspirin and Diabetes Care in Nigeria: Treatment or Exploitation?
}

\author{
Okoro $\mathrm{EO}^{1^{*}}$ and Oyejola ${ }^{2}$ \\ ${ }^{1}$ Division of Hypertension, Diabetes and Therapeutics, University of Ilorin Teaching Hospital, Nigeria \\ ${ }^{2}$ Department of Statistics, University of Ilorin, Nigeria
}

*Corresponding author: Okoro EO, Department of Medicine, University of Ilorin, P.M.B 1515, Ilorin, Nigeria, Tel: +234-31-227153; E-mail: eookoro2003@gmail.com

Received date: May 22, 2015; Accepted date: July 03, 2015; Published date: July 09, 2015

Copyright: ( 2015 , Okoro et al. This is an open-access article distributed under the terms of the Creative Commons Attribution License, which permits unrestricted use, distribution, and reproduction in any medium, provided the original author and source are credited.

\begin{abstract}
Cardiovascular disorders have become leading drivers of untimely deaths almost everywhere. Such deaths are however declining globally due to effective interventions. Low dose aspirin contributes to this reduction when used appropriately through minimization of the risk of coronary heart disease and other occlusive atherosclerotic syndromes that can complicate type 2 diabetes/or hypertension. One local study published in 2004 indicated that aspirin was prescribed for $33 \%$ of patients with type 2 diabetes. Since then, aspirin prescription, as part of standard therapy for type 2 diabetes/or hypertension, has risen steadily with some studies reporting this to be $66 \%-88 \%$; These figures more than double those reported in jurisdictions overseas where occlusive atherosclerotic disorders commonly complicate type 2 diabetes and/or hypertension. Even so, recent transnational data show that cardiovascular deaths linked to type 2 diabetes and or hypertension are not abating in sub-Saharan Africa as in many other regions. This can suggest that interventions in black Africa, if any, maybe less than effective in comparison to areas where health outcomes are improving. Significantly, type 2 diabetes and/or hypertension can behave differently in many black groups within Africa such that occlusive atherosclerotic disorders are less common health consequences even with rising cholesterol levels. In the case of Nigeria, the evidence of cardiovascular health benefits of aspirin, as extensively described in groups overseas, appears hard to find for local cohorts. Indeed what the available data strongly suggest is that effective control of blood pressure is a higher treatment priority for saving Nigerian lives than interventions aimed at retarding the atherosclerotic process. Given these observations, the question ought to be asked whether or not low dose aspirin in type 2 diabetes/hypertension therapies, as locally practiced, is the best way of optimizing limited resources in saving Nigerian lives. This paper examines the evidence.
\end{abstract}

Keywords: Low dose aspirin; Best practice; Diabetes care; Nigeria

\section{Introduction}

The rate at which new cases of type 2 diabetes and/or hypertension now occur is approaching epidemic proportions globally, and these conditions are principal drivers of cardiovascular deaths almost everywhere [1-7]. But while such untimely deaths are declining due to effective interventions, this is not the case in Sub-Saharan Africa including Nigeria [1-3,8]. Indeed, many deaths from diabetes in Nigeria, while patients are receiving treatment care, are largely avertable and can be prevented with effective care [1,2,8-13].

In particular, treatment quality of hypertension, especially when type 2 diabetes is present, frequently fall short of quality threshold committed to by providers and this appears widespread. These reports [8-18] from academic hospitals show that treated patients do not always have their blood pressure lowered to levels that can optimally diminish the risk of untimely deaths and other adverse cardiovascular outcomes. For example, since reporting in 2004, that barely $11 \%$ of patients attending our facility had their BP controlled to less than 90 mmHg [14], more recent data [18] from the same center put this at 23.7\%. Another report [19], involving four different academic hospitals, suggests that only about $40 \%$ of treated patients had blood pressure effectively controlled to desirable targets. These data highlight some improvement in blood pressure control in the last decade but overall control rates remain largely below desired treatment goals. Some experts [3,20-23] however blame this on irregular treatment compliance due to high cost of prescribed therapy.
To be sure inadequate control of $\mathrm{BP}$ is a global phenomenon [23-27] better blood pressure control have been reported with improved utilization of existing remedies [12,25,28]. Indeed, closer examination of published data in Nigeria tend to suggest that treatments that are known to work best for local population are not always optimally utilized; while in many cases needless medications are prescribed and or less effective ones are preferred based on expert opinion even when more expensive[15-17,28-33]. Specifically, many patients are treated as though they were of Northern Hemisphere origin when in reality they are predominantly black Nigerians living in Sub-Saharan Africa [14-17,21,31,34-37] (Figure 1). This can affect treatment cost and outcome due to variation in health consequences of type 2 diabetes and hypertension in different groups requiring different treatment priorities. For example, as at 2004, one local study [38] indicated that low dose aspirin was prescribed for $33 \%$ of patients with type 2 diabetes. Since then, aspirin prescription has increasingly become part of standard therapy for type 2 diabetes/or hypertension with some studies $[14,16,23,30,39]$ reporting prescription frequency as high as $66 \%-88 \%$ in treated patients; these figures more than double those reported in jurisdictions overseas where coronary heart disease/ other occlusive atherosclerotic disorders commonly complicate type 2 diabetes and/or hypertension [35,36,40-42]. In 2012, aspirin therapy became a national best practice in diabetes care [37] (Figure 1) following an intense collaboration between a health professional group, market authorization holders and the Federal government. This has conferred baby aspirin with the status of essential medicine within the context of diabetes/hypertension care thereby creating a multibillion naira industry in which local drug manufacturers are dominant 
players and major beneficiaries [43]. This intriguing initiative raises a number of issues.

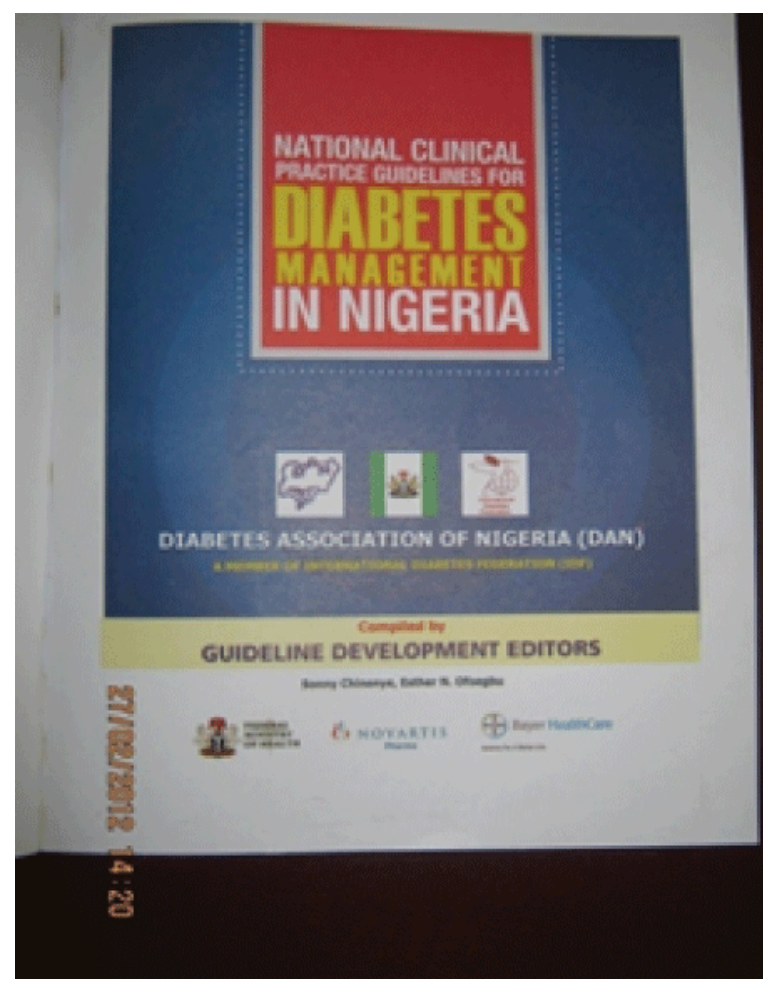

Figure 1: Nigerian National Treatment Guideline for Diabetes

First, as mentioned earlier, recent transnational data $[1,2]$ show that cardiovascular deaths linked to type 2 diabetes and or hypertension are not abating in sub-Saharan Africa as in other regions. This could indicate that interventions applied in black Africa may not be as effective as those applied in regions where health outcomes are improving.

Second, while occlusive atherosclerotic syndromes underlie most untimely cardiovascular deaths particularly in the presence of type 2 diabetes, hypertension and/or elevated cholesterol in those regions, this is not the case in sub-Saharan Africa which has the lowest disease burden of such occlusive atherosclerotic disorders including coronary heart disease [CAD] and large vessel stroke[1,2].

In the case of Nigeria, health market, despite some reports $[44,45]$ of more cases of CAD in recent decades, accumulated data [3,4,46-55] continue to show that atherosclerotic disorders remain infrequent. Specifically, though diagnostic tests e.g. coronary angiography required to confirm suspected cases may be lacking in many academic hospitals, autopsy data $[3,4,49-55]$ consistently show that occlusive atherosclerotic disorders remain an uncommon complication in people dying from type 2 diabetes and hypertension in Nigeria.

Third and even more compelling, it remains unclear how low dose aspirin can be expected to improve treatment quality/outcome of type 2 diabetes and/or hypertension when no supporting evidence of its health benefits in any local cohort exists. This is a treatment option that appears to follow similar recommendations by scholars, professional bodies and consumer protection agencies in North
America and Europe made from the perspectives of their home populations [56-61].

In this context, widespread implementation of this treatment guideline may result in waste of scarce resources and an unnecessary exposure of many patients to aspirin related harm particularly as high risk hypertension or type 2 diabetes appear to have different health consequences in most people affected in Nigeria compared to similar groups overseas where baby aspirin seem beneficial. The question is why does such unrestrained use of aspirin continue?

An oral presentation of part of this communication was made to World Health Organization meeting of National Medicines Regulatory Authorities in Rome, Italy in 2013 entitled "Message from the dead in Nigeria" [62] and re-echoed in a global debate/open forum discussion on medicines use entitled Risk: whose/what risk by a panel of experts of which the lead author was part [63].

\section{Disease Mechanisms of Hypertension/Diabetes}

To start with, several local studies $[14,16,19]$ show that an increasing number [in some series as high as 60-70\%] of those attending university based diabetes clinics have elevated blood pressure. This high disease overlap between hypertension and type 2 diabetes as well as genetic studies [64-67] suggest that both conditions may share a common disease mechanism with both conditions being two extreme clinical expressions of the same pathologic entity. Even at that, elevated blood pressure seem the dominant mechanism that drives the disease process in that; lowering blood pressure is often more effective in preventing untimely deaths and other adverse cardiovascular events related to diabetes than tighter blood glucose regardless of race/ethnicity and geographic location [35,36,68-71].

On the other hand, while the risk factors for occlusive atherosclerotic syndromes are not fully understood in black Africa $[2,72]$, autopsy data $[3,4,49-55]$ consistently show that heart attack, stroke and other occlusive atherosclerotic disorders are less common health consequences of hypertension and type 2 diabetes despite rising cholesterol level in the Nigeria population. This could mean that atherosclerosis in Nigerians with type 2 diabetes and/or hypertension may not be a high risk phenomenon that progressively results in occlusive clinical syndromes requiring additional interventions beyond blood pressure reduction and or diabetes control [11,24,26,73-74]. This large body of compelling autopsy data [3,4,49-55] consistently shows that often less than $10 \%$ of people in Nigeria dying from hypertension and or type 2 diabetes had occlusive atherosclerotic diseases as the cause of death and this figure has remained largely the same in the last $40-50$ years. This is not to say that stroke, heart diseases and other cardiovascular conditions are uncommon in local clinical practice. As a matter of fact these cardiovascular disorders are emerging as leading drivers of untimely deaths and chronic disabilities in Nigeria [3-7] but most cases result from uncontrolled blood pressure and rarely due to occlusive atherosclerosis where platelets aggregation is pathologically involved. Furthermore, many risk assessment tools [58-61] used to determine therapeutic priorities and treatment intensity have not been extensively validated in Nigeria particularly as risk factors for adverse cardiovascular outcome do not have the same potency across all racial/ ethnic groups [75-78]. This disease heterogeneity suggest that blood pressure reduction should be a higher treatment priority in saving Nigerian lives than interventions like daily baby aspirin aimed at retarding the atherosclerotic process which is unlikely to deliver the 
same health benefits inmost black Nigerians with type 2 diabetes and or hypertension as observed elsewhere.

\section{Evolution of Aspirin Therapy in Diabetes/ Hypertension}

Nevertheless, the evidence $[59,61,79,80]$ indicating that daily babyaspirin can lower the risk of recurrent heart attack, stroke and other adverse atherosclerotic cardiovascular events i.e. prevent further attacks in people already affected, is persuasive. It is therefore not surprising that many scholars, professional health bodies and national medicines regulatory authorities support using aspirin this way especially in groups where occlusive atherosclerotic syndromes frequently complicate type 2 diabetes/or hypertension. However, not every racial/ethnic group even within the same national boundaries is equally affected [36,75-78]. Therefore it is established that this intervention rarely apply to everyone with type 2 diabetes/or hypertension especially black people of African descent including Nigerians who appear less susceptible to occlusive atherosclerosis compared to other racial/ethnic groups where aspirin therapy has been firmly recognized as a treatment priority and cost effective [36,59-61,75-78]. Even in Europe and North America where aspirin has been extensively studied, there is very little evidence that baby aspirin benefits everyone with hypertension or and diabetes as is apparently recommended in Nigeria [30,35,36,81-83] (Figure 1). In rich countries where this treatment originate and $\mathrm{CAD} /$ other occlusive atherosclerotic complications are the commonest causes of untimely death in type 2 diabetes and hypertension, low dose aspirin therapy has not been convincingly shown to prevent first-time cardiovascular events even among high risk individuals [80-83]. The implication of this for clinical practice is that prescribing daily low dose aspirin is unlikely to prevent first time heart attack and stroke even in those with type 2 diabetes, hypertension and elevated cholesterol at high risk of atherosclerotic disorders. Given that aspirin, even in low dose can result in death from unintended effects [82-85], more so as its use can represent waste of resources for which no health benefit is likely, it is not surprising that United States Food and Drug Agency [USFDA] recently declined approval of marketing authorization for this indication [86].Consequently, as is the norm that before any medicine especially one for public health conditions like hypertension and type 2 diabetes are made available for general use, one would assume that evidence of health benefit[s] already exist in the population of intended use; particularly for a potentially dangerous medication like aspirin and for which users are also to bear additional treatment cost daily for life. Curiously, extensive literature search failed to show any such evidence nor was any on-going post marketing study intended to determine the risk-benefit/cost effectiveness of using aspirin this way in any Nigerian cohort found. This is baffling for a population of 173.6 million that is rapidly expanding and also the largest health market of blacks anywhere in the world [87].

\section{Price-Ringing and Cartel}

In any case, over the last decade, a $75 \mathrm{mg}$ tablet of aspirin has become widely available in Nigeria specifically formulated to "prevent stroke, heart attack and other adverse cardiovascular events" as well as indicated for treating aches, pains and fever [see product information [88]. This local brand (sachets) (Figure 2) entered the market at a cost of two naira per tablet [equivalent of 4 US cents] to consumers. But for many decades before then, aspirin was widely accessed as over-thecounter medication at a higher dosage [300 mg] tablet form (single stand-alone white tablet) (Figure 2) sold for one naira per tablet [equivalent to two US cents] at a local pharmacy shop when last purchased. The latter is however increasingly becoming scarce in the open market; and this could be attributed to an almost ubiquitous availability of paracetamol as home remedy for aches, pains and fever. Nevertheless, diverse brands of this higher dosage form in Nigeria health market is pharmacologically similar to and could be used for almost all indications for which the $75 \mathrm{mg}$ tablet-formulation is widely prescribed in many diabetes/hypertension treatment facilities $[16,18,28,38,39,88,89]$. Indeed prescribing the $300 \mathrm{mg}$ tablet formulation in place of the $75 \mathrm{mg}$ tablet form can lower the daily treatment cost by nearly $200 \%$ of the current cost of aspirin therapy patients with hypertension and/or diabetes are made to bear.

Not only that, baby aspirin product, a prescription medicine in the context of hypertension/diabetes therapy is regularly advertised on National television as a daily remedy for preventing sudden death due to heart attack and stroke. This can stimulate demand and expand customer base for this indication in the wider population but what is not often mentioned is that the types of stroke and heart conditions that commonly occur in Nigeria are rarely due to occlusive atherosclerosis but almost invariably result from uncontrolled blood pressure in over $90 \%$ of cases and this is usually in those with hypertension and or type 2 diabetes [3,4,49-55]. At the current price of five naira per tablet per day, this amount can pay for up to five days of antihypertensive therapy with low dose thiazide diuretics which is capable of lowering blood pressure to targets that optimally diminish the risk of untimely deaths and other cardiovascular events particularly in many black people, at least initially [39,90,91]. Five naira, equivalent to about ten US cents [by current exchange rate of 197 naira to one US dollar] may not seem much by purchasing power available in many high income countries, but over a lifetime of treatment, this can mean a lot of money for many struggling Nigerians, majority of who are poor and disproportionately affected by hypertension and type 2 diabetes [20,30 ]. The recommended national minimum wage is 18000 naira monthly but not every employer pays this and many people willing to work cannot find employment. Incidentally, the price increase of baby aspirin alluded to earlier has remained at five naira virtually across all local brands including newer entrants. Such price stability can suggest a lack of active competition/ market price control mechanism which raises the possibility of a priceringing cartel. It is worth mentioning that health care services in Nigeria are delivered mostly by the private sector on a cash and carry basis. Even where health service is subsidized by government, consumers still pay $70-90 \%$ of total treatment cost at the point of use regardless of need and ability to pay [92]. The implication of this is that many ordinary citizens with hypertension/type 2 diabetes can fail to receive effective care because badly needed resources that could contribute in optimizing blood pressure control are diverted in paying for a prescribed medicine that adds little or nothing to treatment quality/outcome.

\section{Conclusion}

Although paying higher cost for lower quality is not an unusual experience in Nigeria [93] but labeling a medicine essential as now appears to be the case with baby aspirin can create a huge marketing opportunity. This can attract powerful interests not all of which may advance public health. More worrisome is that quality assurance/ control processes in patient care that can be expected to ensure treatments are delivered in accordance with the evidence of what work 
best for the service population seem inoperative even in academic health centers. Not only that, high profile professors as shapers of medical practice sometimes promote particular interventions in media events organized by market authorization holders even where no supporting evidence exists. This can confer legitimacy on dubious therapeutics claims [94,95]. Apart from fuelling inappropriate use of medicines, this can also promote the notion that other people's treatment priorities should be adopted everywhere without prior determination whether or not such therapies are equally beneficial to local population.

Many fair minded scholars would agree that risks that should determine treatment priorities ought to be those indigenous to the population of interest especially in conditions like type 2 diabetes and hypertension which exhibit disease variability with different health consequences in different groups/individuals. Massively introducing treatments that work well elsewhere without re-calibration for local health needs/priorities as now seem to be the case with baby aspirin in the treatment of hypertension and type 2 diabetes in Nigeria can inadvertently turn a disease condition very few have or are ever likely to have into a public health emergency. In the process, this can create a huge and ever expanding market for dumping medicinal products of little relevance to the health needs/priorities of Nigeria and its people all in the name of national best practice (Figure 1). What seems surprising is how government agencies charged with the responsibility of ensuring that medicines which enter the health system represent the best value for money can become bystanders as unsuspecting consumers are exploited with such unrestrained prescription of aspirin. This can undermine the capacity of health systems to deliver effective and affordable care based on evidence. This is increasingly becoming of concern to many responsible governments dedicated to serving their nationals well within available resources [96,97]. In this circumstance it, may be difficult to shake off any accusation that prescribers expected to act in the best interest of their patients or communities are not part of an elaborate scheme which sees patients more as revenue source than anything else.

Unfortunately, such behavior can erode public confidence in orthodox health care services and damage the reputation of Medicine as a caring profession.

In summary, this paper argues that the scientific/ethical grounds that can justify the almost universal use of aspirin in type 2 diabetes and/or hypertension especially as primary prevention for atherosclerotic disorders as recommended by local experts is yet to emerge. This calls for greater restriction of baby aspirin availability at all tiers of care with closer monitoring of its use to minimize misuse/ abuse. Moreover, making the $300 \mathrm{mg}$ aspirin tablet formulation as available as the $75 \mathrm{mg}$ tablet formulation could give prescribers and consumers greater choice in lowering treatment cost for individuals requiring low dose aspirin therapy especially for secondary prevention in those with known occlusive atherosclerotic disease, but are unable to pay the higher cost of using the $75 \mathrm{mg}$ tablet formulation that comes with more convenient packaging (Figure 2).

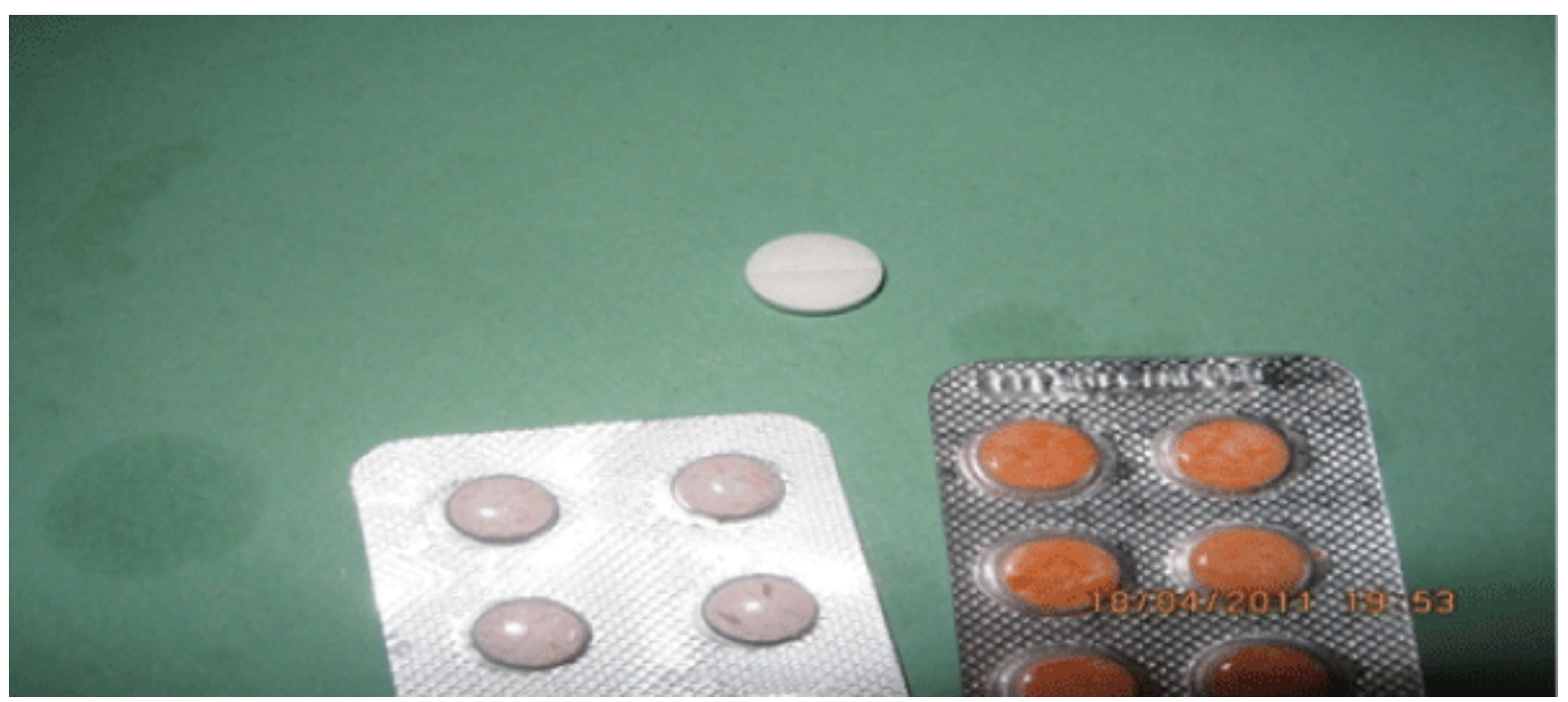

Figure 2: Some brands of $75 \mathrm{mg}$ aspirin tablet in sachet and a $300 \mathrm{mg}$ aspirin tablet (white)

\section{Dedication}

This work is dedicated to the memory of Godfrey Ambakedermo Okoro [Col.].

\section{References}

1. GBD Mortality and Causes of Death Collaborators (2015) Global, regional, and national age-sex specific all-cause and cause-specific mortality for 240 causes of death, 1990-2013: a systematic analysis for the Global Burden of Disease Study 2013. Lancet 385: 117-171.
2. Gaziano TA, Bitton A, Anand S, Abrahams-GS, Murphy A (2010) Growing epidemic of coronary heart disease in low- and middle-income countries. Curr Probl Cardiol 35: 72-115.

3. Mbakwem AC, Oke DA, Ajuluchukwu JN, Abdulkareem FB, Ale O, et al. (2009) Trends in acute emergency room hypertension related deaths: an autopsy study. Niger J Clin Pract 12: 15-19.

4. Izegbu MC (2007) Post-mortem data of Causes of death. Nig. Hosp Pract[4-6], $106-112$.

5. Unachukwu CN, Uchenna DI, Young E (2008) Pattern of noncommunicable diseases among medical admissions in Port Harcourt, Nigeria. African Journal of Endocrinology Metabolism 7: 1-4. 
6. Adebayo ADA, Fawole O, Bamgboye (2012) Morbidity and mortality patterns of medical admissions in a Nigerian secondary health care hospital. Afr J Med med sci 41: 13-20.

7. Ekere AU, Yellowe BE, Umune S (2005) Mortality patterns in the accident and emergency department of an urban hospital in Nigeria. Niger J Clin Pract 8: 14-18.

8. Kolo PM, Jibrin YB, Sanya EO, Alkali M, Peter Kio IB (2012) Hypertension-Related Admissions and Outcome in a Tertiary Hospital in Northeast Nigeria. International Journal of Hypertension 2012: 1-6.

9. Eregie A, Unadike BC (2010) Common causes of morbidity and mortality amongst diabetic admissions at the University of Benin Teaching Hospital, Benin City, Nigeria. Pak J Med Res 49: 89-93.

10. Chijioke A, Adamu AN, Makusidi AM (2010) Mortality pattern among type 2 diabetes patient in Ilorin, Nigeria. JEMDAS 15: 1-4.

11. Kolawole BA, Ajayi AA (2000) Prognostic indices for intra-hospital mortality in Nigerian diabetic NIDDM patients. Role of gender and hypertension. J Diabetes Complications 14: 84-89.

12. Wenxin Xu, Saveli IG, Maria S, Alexander T (2015) Optimal systolic blood pressure target, time to intensification, and time to follow-up in treatment of hypertension: population based retrospective cohort study. BMJ 350: h158.

13. Okoro EO, Yusuf M, Salawu HO, Oyejola BA (2007) Outcome of diabetic hyperglycemic emergencies in a Nigerian Cohort J. Chinese Clinical Med 2: 1-7.

14. Okoro EO, Oyejola BA (2004) Inadequate control of blood pressure in Nigerians with diabetes. Ethn Dis 14: 82-86.

15. Arije A, Kuti M, Fasanmade A (2007) Control of hypertension in Nigerians with Diabetes Mellitus: A report of the Ibadan Diabetic / Kidney Disease Study Group. Int J Diabetes \& Metabolism15: 82-86.

16. Ajayi EA, Ajayi AO, Olalekan OE (2010) Treatment to targets in type 2 diabetics: analysis of out-patients practice at a remote Western Nigerian hospital. Internet Journal of Medical Update5: 8-14.

17. Ogbonna BO, Ezenduka CC, Opera CA, Ahara LG (2014) Type-2 Diabetes in a Tertiary Hospital in Nigeria. International Journal of Innovative Research \& Development 3: 494-502.

18. Olarewaju TO, Aderibigbe A, Chijioke A, Sanya EO, Busari OA, et al. (2011) Descriptive analysis of blood pressure control among among treated hypertensive patients in a tertiary hospital in Nigeria. Afr J Med Med Sci 40: 207-212.

19. Akhuemokhan IK, Ehusani-Anumah FO, Ogbera AO, Ikem RT, Puepet F (2008) Hypertension in Nigerians with type 2 diabetes: a multicentre survey. Diabetes International 7: 16-18.

20. Enwere OO, Salako BL, Falade CO (2006) Prescription and cost consideration at a diabetic clinic in Ibadan, Nigeria: a report. Annals of Ibadan Postgraduate Medicine 4: 35-39.

21. Ilesanmi OS, Ige OK, Adebiyi AO (2012) The managed hypertensive: the costs of blood pressure control in a Nigerian town. Pan Afr Med J 12: 96.

22. Suleiman IA, Siasia WO, Egbesu IE (2014) Outcomes of anti-diabetic therapy in a Niger Delta referral centre, in Nigeria. West African Journal of Pharmacy 25: 46-54.

23. Isezuo AS, Njoku CH (2003) Blood pressure control among hypertensives managed in a specialised health care setting in Nigeria. Afr J Med Med Sci 32: 65-70.

24. Kramer H, Han C, Post W, Goff D, Diez-Roux A, et al. (2004) Racial/ ethnic differences in hypertension and hypertension treatment and control in the multi-ethnic study of atherosclerosis (MESA). Am J Hypertens 17: 963-970.

25. Qiuping G, Burt VI, Dillion CF, Yoon S (2012) Trends in antihypertensive medication use and blood pressure control among United States adults with hypertension: The National Health and Nutrition Examination Survey, 2001 to 2010 Circulation,126, 2015-2114.

26. Hunte HE, Mentz G, House JS, Schulz AJ, Williams DR et al. (2012) Variations in hypertension-related outcomes among Blacks, Whites and Hispanics in two large urban areas and in the United States. Ethn Dis 22: 391-397.
27. Gutierrez J, Williams OA (2014) A decade of racial and ethnic stroke disparities in the United States. Neurology 82: 1080-1082.

28. Adigun AQ, Ishola DA, Akintomide AO, Ajayi AA (2003) Shifting trends in the pharmacologic treatment of hypertension in a Nigerian tertiary hospital: a real-world evaluation of the efficacy, safety, rationality and pharmaco-economics of old and newer antihypertensive drugs. J Hum Hypertens 17: 277-285.

29. ObinnaIkechukwuEkwunife, Patrick OU, IzuchukwuLovethNwatu (2010), Prevalence, awareness, treatment and control of hypertension in a Nigerian population. Health 2: 731-735.

30. IE Chiazor, Azuka CO (2012) Assessment of Hypertension Care in a Nigerian Hospital. Tropical Journal of Pharmaceutical Research 11: 137-145.

31. Ajayi AA, Oyewo EA, Ladipo GO, Akinsola A (1989) Enalapril and hydrochlorothiazide in hypertensive Africans. Eur J Clin Pharmacol 36: 229-234.

32. Bello SI (2012) Adherence and generic substitution among hypertensive patients in a specialist hospital. Nigeria Global Journal of Medical Research 12: 33-42.

33. Unadike BC, Eregie A, Ohwovoriole AE (2008) Profile of antihypertensive use and hypertension control among persons with diabetes mellitus in Benin-City, Nig. Nig Hosp Pract 2: 106-109.

34. Jennings GL, Touyz RM (2013) Hypertension guidelines: more challenges highlighted by Europe. Hypertension 62: 660-665.

35. UKPDS 38 (1998) Tight blood pressure control and the risk of macrovascular and microvascular complications in type 2 diabetes. UK Prospective Diabetes Study Group. BMJ 317: 703-713.

36. ALLHAT Authors (2002) Major outcome in high-risk hypertensive patients randomized to angiotensin converting enzyme inhibitor or calcium channel blocker vs diuretic: The anti hypertensive and Lipidlowering Treatment to prevent Heart Attack Trial. JAMA 288: 2981-2997.

37. Sonny C, Easther O, (2011) National Clinical Practice Guidelines for Diabetes Management in Nigeria. Diabetes Association of Nigeria ISBN: 978-978-919-051-5.

38. Kolawole BA, Adebayo RA, Aloba OO (2004) An assessment of aspirin use in a Nigerian diabetes outpatient clinic. Niger J Med 13: 405-406.

39. Salawu FK, Olokoba AB, Danburam A (2008) An Audit of Aspirin Use For Prevention Of Vascular Complications In Nigerians With Diabetes Mellitus. Sahel Medical Journal 11: 134- 136.

40. Brown DW1, Shepard D, Giles WH, Greenlund KJ, Croft JB (2005) Racial differences in the use of aspirin: an important tool for preventing heart disease and stroke. Ethn Dis 15: 620-626.

41. Law EH, Scot H, Simpson BS (2010) Aspirin Use Rates in Diabetes: A Systematic Review and Cross-Sectional Study. Canadian J Diabetes 34: 211-217.

42. Hira RS, Kennedy K, Nambi V, Jneid H, Alam M, et al. (2015) Frequency and Practice-Level Variation in Inappropriate Aspirin Use for the Primary Prevention of Cardiovascular Disease Insights from the National Cardiovascular Disease Registry's Practice Innovation and Clinical Excellence Registry. J Am Coll Cardiol 65: 111-121.

43. Federal Ministry of Health (2005) National Drug Policy. Abuja, Nigeria.

44. Oyati AL, Danbauchi SS, Alhassan MA, Isa MS (2005) Is the incidence of acute myocardial infarction in Nigeria increasing? Annals Afr Medi 4: 132-135.

45. Kolo PM, Fasae AJ, Aigbe IF, Ogunmodede JA, Omotosho AB (2013) Changing trend in the incidence of myocardial infarction among medical admissions in Ilorin, north-central Nigeria. Niger Postgrad Med J 20: 5-8.

46. Kolo PM, Omotoso ABO, Adeoye PO, Fasae AJ, Adamu UG et al. (2009) Echocardiography at the University of Ilorin Teaching Hospital, Nigeria: A three years audit. Research Journal of Medical Sciences 3: 141-145.

47. Falase AO, Oladapo OO, Kanu EO (2001) Relatively low incidence of myocardial infarction in Nigerians. Trop Cardiology 27: 45-47.

48. Mukadas OA, Misbau U (2009) Incidence and patterns of cardiovascular disease in North-Western Nigeria. Niger Med J 50: 55-57. 
49. Obiora CC, Amakiri CNT (2012) Systematic analysis of sudden natural deaths at Braith Waitt Memorial Specialist Hospital, Port-Harcourt, Nigeria. Nig Health J 12: 47-51.

50. Rotimi O, Ajayi AA, Odesanmia WO (1998) Sudden unexpected death from cardiac causes in Nigerians: A review of 50 autopsied cases. International Journal of Cardiology 63: 111-115.

51. Akinwusi PO, Komolafe AO, Olayemi OO, Adeomi AA (2013) Pattern of sudden death at Ladoke Akintola University of Technology Teaching Hospital, Osogbo, South West Nigeria. Vasc Health Risk Manag 9: 333-339.

52. Osuntokun BO, Bademosi O, Akinkugbe OO, Oyediran AB, Carlisle R (1979) Incidence of stroke in an African City: results from the Stroke Registry at Ibadan, Nigeria, 1973-1975. Stroke 10: 205-207.

53. Williams AO, Loewenson RB, Lippert DM, Resch JA (1975) Cerebral atherosclerosis and its relationship to selected diseases in Nigerians: a pathological study. Stroke 6: 395-401.

54. Pelemo OE, Sabageh D, Komolafe AO, Sabageh AO, Odesanmi WO (2014) An autopsy review of sudden unexpected natural deaths in a suburban Nigerian population. Population Health Metrics 12: 26-31.

55. Mandong BM, Manasseh AN, Ugwu BT (2006) Medicolegal autopsies in North Central Nigeria. East Afr Med J 83: 626-630.

56. American Diabetes Association (2013) Standards of medical care in diabetes-2013. Diabetes Care 36 Suppl 1: S11-66.

57. Odili VU, Oghagbon EK, Ugwa NA, Ochei UM, Aghomo OE (2008) Adherence to international guidelines in the management of hypertension in a tertiary hospital in Nigeria. Tropical J Pharmaceutical Res 7: 945-952.

58. Goff DC Jr, Lloyd-Jones DM, Bennett G, Coady S, D'Agostino RB, et al. (2014) (2014) 2013 ACC/AHA Guideline on the Assessment of Cardiovascular Risk: A Report of the American College of Cardiology/ American Heart Association Task Force on Practice. Circulation 129: S49-S73.

59. Weisman SM, Graham DY (2002) Evaluation of the benefits and risks of low-dose aspirin in the secondary prevention of cardiovascular and cerebrovascular events. Arch Intern Med 162: 2197-2202.

60. Hall SL, Lorenc $\mathrm{T}$ (2010) Secondary prevention of coronary artery disease. Am Fam Physician 81: 289-296.

61. Antithrombotic Trialists' Collaboration (2002) Collaborative metaanalysis of randomised trials of antiplatelet therapy for prevention of death, myocardial infarction, and stroke in high risk patients. BMJ 324 71 .

62. Okoro EO (2013) World Health Organization Centers Meeting, Rome, Italy, September/October 2013[ see editorial, Uppsala Reports 63,2013 atUR63 October 2013 www.who-umc.org

63. Okoro E (2014) Why is the treatment quality of hypertension in type 2 diabetes so poor when effective medicines are available and; what can we do about it in a way that benefits all stakeholders ?- what should determine treatment priorities of hypertension in type 2 diabetes? RISK:what risk? Whose risk? Uppsala monitoring centre research conference 2014 on Patient safety, May 22-23. Uppsala, Sweden.www.who.umc.org/research.

64. Okoro EO, Oyejola BA, Jolayemi ET (2002) Pattern of salt taste perception and blood pressure in normotensive offspring of hypertensive and diabetic patients. Ann Saudi Med 22: 249-251.

65. Ng MC, So WY, Cox NJ, Lam VK, Cockram CS et al. (2004) Genomewide scan for type2 diabetes loci in Hong Kong Chinese and confirmation of a susceptibility locus on chromosome lq21-q25. Diabetes 53: $1609-1613$.

66. Ologe FE, Okoro EO, Oyejola BA (2005) Hearing function in Nigerian children with a family history of type 2 diabetes. Int J Pediatr Otorhinolaryngol 69: 387-391.

67. Ross KA (2011) Evidence for somatic gene conversion and deletion in bipolar disorder, Crohn's disease, coronary artery disease, hypertension, rheumatoid arthritis, type-1 diabetes, and type-2 diabetes. BMC Med 9: 12 .
68. Turnbull F, Neal B, Algert C, Chalmers J, Chapman N, et al. (2005) Effects of different blood pressure-lowering regimens on major cardiovascular events in individuals with and without diabetes mellitus: results of prospectively designed overviews of randomized trials. Arch Intern Med 165: 1410-1419.

69. Ganesh J, Viswanathan V (2011) Management of diabetic hypertensives. Indian J Endocrinol Metab 15 Suppl 4: S374-379.

70. ACCORD Study Group, Cushman WC, Evans GW, Byington RP, Goff DC Jr, et al. (2010) Effects of intensive blood-pressure control in type 2 diabetes mellitus. N Engl J Med 362: 1575-1585.

71. Cheung BM, Li C (2012) Diabetes and hypertension: is there a common metabolic pathway? Curr Atheroscler Rep 14: 160-166.

72. Laurence EC, LombardL, Volmink JY (2011) Risk factors for myocardial infarction and stroke in Africa. SA Heart 8: 12-23.

73. Erete EI, Ogun OG, Oladapo OO, Akang EE (2012) Prevalence and severity of atherosclerosis in extra cranial carotid arteries in Nigeria: an autopsy study. BMC Cardiovasc Disord 12: 106.

74. Ogbera AO, Chinenye S, Onyekwere A, Fasanmade O (2007) Prognostic indices of diabetes mortality. Ethn Dis 17: 721-725.

75. Onwuanyi A, Hodges D, Avancha A, Weiss L, Rabinowitz D, et al. (1998) Hypertensive vascular disease as a cause of death in blacks versus whites: autopsy findings in 587 adults. Hypertension 31: 1070-1076.

76. Karter AJ, Ferrara A, Liu JY, Moffet HH, Ackerson LM, et al. (2002) Ethnic disparities in diabetic complications in an insured population. JAMA 287: 2519-2527.

77. Sacco RL, Boden-Albala B, Abel G, Lin IF, Elkind M, et al. (2001) Raceethnic disparities in the impact of stroke risk factors: the northern Manhattan stroke study. Stroke 32: 1725-1731.

78. Markus HS, Khan U, Birns J, Evans A, Kalra L, et al. (2007) Differences in Stroke subtypes between Black and White Patients with Stroke: The south London Ethnicity and Stroke Study. Circulation 116: 2157-2164.

79. Belch J, MacCuish A, Campbell I, Cobbe S, Taylor R, et al. (2008) The prevention of progression of arterial disease and diabetes (POPADAD) trial: factorial randomised placebo controlled trial of aspirin and antioxidants in patients with diabetes and asymptomatic peripheral arterial disease. BMJ 337: a1840.

80. Okada S, Morimoto T, Ogawa H, Kanauchi M, Nakayama M, et al. (2011) Differential Effect of Low-Dose Aspirin for Primary Prevention of Atherosclerotic Events in Diabetes Management-A sub analysis of the JPAD trial. Diabetes Care 34: 1277-1283.

81. Pignone M, Earnshaw S, Tice JA, Pletcher MJ (2006) Aspirin, statins, or both drugs for the primary prevention of coronary heart disease events in men: a cost-utility analysis. Ann Intern Med 144: 326-336.

82. Ikeda Y, Shimada K, Teramoto T, Uchiyama S, Yamazaki T, et al. (2014) Low-dose aspirin for primary prevention of cardiovascular events in Japanese patients 60 years or older with atherosclerotic risk factors: a randomized clinical trial. JAMA 312: 2510-2520.

83. Huynh K (2015) Atherosclerosis: low-dose aspirin failed to improve cardiovascular outcomes. Nat Rev Cardiol 12: 3.

84. Akinwusi O, Oluyombo R, Ogunro PS, Adeniji AO, Okunola OO, et al. (2013) Low dose aspirin therapy and renal function in elderly patients. Int J Gen Med 6: 19-24.

85. Lanas A, Wu P, Medin J, Mills EJ (2011) Low doses of acetylsalicylic acid increase risk of gastrointestinal bleeding in a meta-analysis. Clin Gastroenterol Hepatol 9: 762-768.

86. FDA, Use of Aspirin for Primary Prevention of Heart Attack and Stroke.

87. www.worldbank.org/en/country/nigeria.

88. www.drugstoc.biz/productand www.emdexafrica.com

89. Bamigbola EA, Ibrahim MA, Attama AA, Arute JE (2009) Comparative Bioequivalence Assessment of Aspirin Tablets Marketed in Nigeria. International Journal of Health Research 2: 375-379.

90. Okoro EO, Jolayemi ET, Oyejola BA (2001) Observations on the use of low dose hydrocholorothiazide in the treatment hypertension in Diabetic Nigerians. Heart Drug 1: 83-88. 
Citation: Okoro EO, Oyejola (2015) Aspirin and Diabetes Care in Nigeria: Treatment or Exploitation? . J Clinic Res Bioeth 6: 227. doi: $10.4172 / 2155-9627.1000227$

Page 7 of 7

91. Okoro EO, Oyejola BA (2005) Long term effects of hydrochlorothiazide on diabetic control and blood pressure in Nigerians. Kuwait Med J 37: 18-21.

92. Okoro EO, Kolo PM, Davies, AE (2009) Low-cost is the key to quality outcome in type 2 diabetes in Nigeria. In: Lignalli AT (ed.) Handbook of type 2 diabetes in the middle aged and elderly.

93. www.ngrguaediannews.com

94. http:// thenationonlineng.net

95. http://www.ngrguardiannews.com
96. Ndindjock R1, Gedeon J, Mendis S, Paccaud F, Bovet P (2011) Potential impact of single-risk-factor versus total risk management for the prevention of cardiovascular events in Seychelles. Bull World Health Organ 89: 286-295.

97. Neuman J ,Korenstein D, Ross JS, Keyhani S (2012) Prevalence of financial conflicts of interest among panel members producing clinical guidelines in Canada and United States: a cross sectional study. BMJ 16: 96-102. 